\title{
FOREWORD
}

\section{Special issue in honour of Prof. Reto J. Strasser}

\author{
HAZEM M. KALAJI ${ }^{*+}{ }^{\text {AND VASILIJ GOLTSEV }}{ }^{* *}$
}

Department of Plant Physiology, Institute of Biology, Warsaw University of Life Sciences SGGW, 02-776 Warsaw, Poland ${ }^{*+}$ Department of Biophysics and Radiobiology, Sofia University "St. Kl. Ohridski”, 1164 Sofia, Bulgaria**

${ }^{+}$Corresponding author; e-mail: hazem@kalaji.p1

This Special issue of Photosynthetica has been compiled to honour Professor Reto Jörg Strasser's $75^{\text {th }}$ birthday which was on 28 December, 2018. Reto (Fig. 1) has been a famous scientist in the field of photosynthesis and chlorophyll $a$ fluorescence since the beginning of his $\mathrm{PhD}$ studies in 1968 at University of Bern. In 1976, he got a habilitation degree in photobiology at the same university and within the next year (1977) he moved to the USA to work as Principal Acting Investigator (PAI) at University of California, San Diego (UCSD).

In 1978, Reto came back to Switzerland and started to work as the First Assistant at the Laboratory of Plant Physiology, University of Geneva, where he got the Habilitation degree in Bioenergetics. In 1980, he acted as Professor and Director of the Bioenergetics Laboratory, University of Stuttgart, Germany. Later on (1986), he became the Director of the Institute of Biology at this university. From 1987 until his retirement on 1 August 2009, Reto worked as the Professor in Plant Physiology and Bioenergetics and Director of the Experimental Station of Botany at the very famous Bioenergetics Laboratory, Jussy, Geneva (Photo. Fig. 2), where he developed his "unique scientific school" related to analysis of plant photosynthetic efficiency by the use of chlorophyll $a$ fluorescence measurements (JIP or OJIP test).

Prof. Reto Strasser has been considered as a pioneer of the highest order and a visionary. His discoveries and findings were proved by thousands of publications, especially those related to JIP-test (Fig. 3). The so called JIP-test, published earlier by Reto, characterizes PSII and the photosynthetic electron transport activity in samples illuminated after a period of darkness, and derived by using not only the minimum $\left(\mathrm{F}_{0}\right)$ and maximum $\left(\mathrm{F}_{\mathrm{M}}\right)$

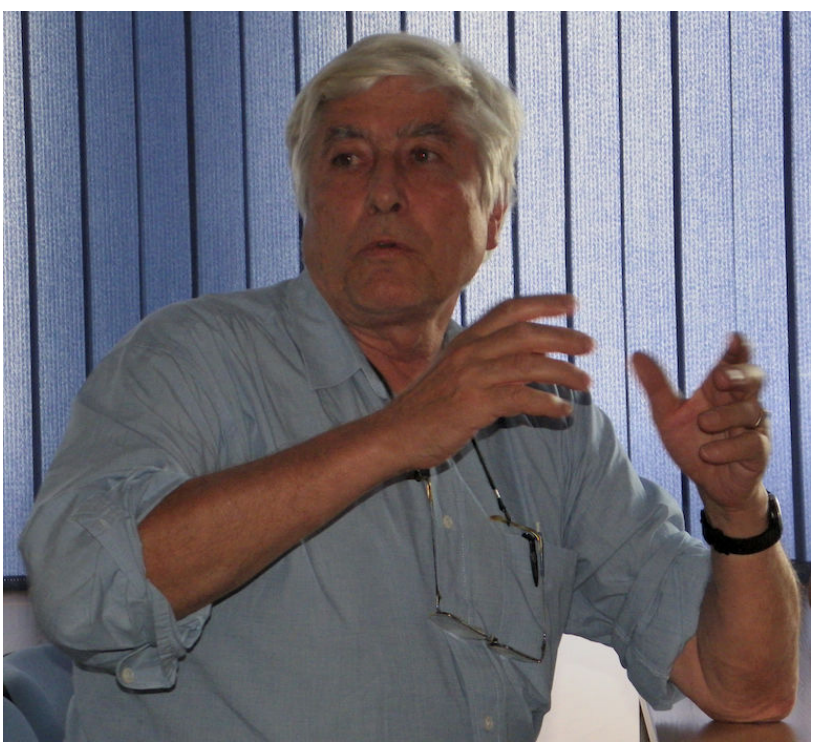

Fig. 1. Prof. Reto Strasser: The excellent scientist, teacher, mentor, visionary, and innovator.

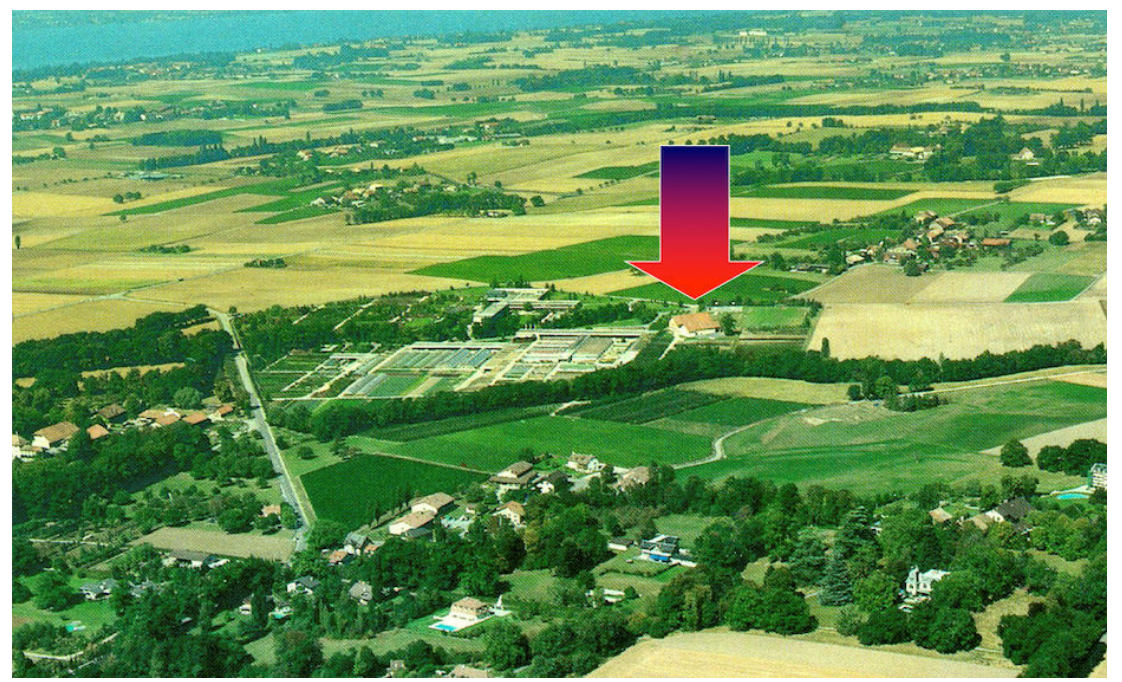

Fig. 2. Bioenergetics Laboratory established by Prof. Reto Strasser in the Experimental Station of Botany, Jussy, Geneva, Switzerland. 


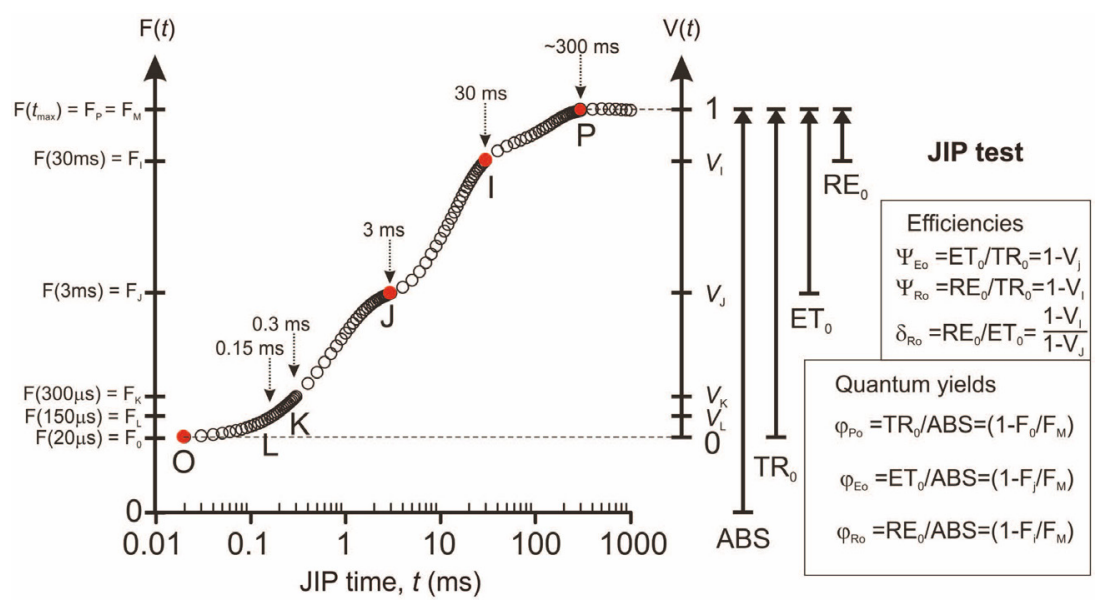

Fig. 3. The chlorophyll $a$ fluorescence induction curve with the particular OJIP test steps marked at 3,000 $\mu \mathrm{mol}$ (photon) $\mathrm{m}^{-2} \mathrm{~s}^{-1}$ during a 1-s measurement (Kalaji et al. 2014).

fluorescence, but also fluorescence levels at $0.3 \mathrm{~ms}\left(\mathrm{~F}_{\mathrm{K}}\right)$, at $3 \mathrm{~ms}\left(\mathrm{~F}_{\mathrm{J}}\right)$, and at $30 \mathrm{~ms}\left(\mathrm{~F}_{\mathrm{I}}\right)$ (Govindjee et al. 2019). The JIP-test is tightly connected to the Energy Flux Theory (EFT) developed by Strasser 35 years ago (TsimilliMichael 2020).

The first works related to developing the JIP test idea, calculations, and formulas were published in the form of "Yellow Books" that were published between 1967 and 2010 as a "new library" in photosynthesis research (Fig. 4). The main published papers were prepared by Alexandrina Stirbet and Reto himself in 2012, as a list for Yellow Books between 1967 to 2009. Many of them contain first hand-written formulas, concepts, theories, and schemes related to the flux and fate of light energy in photosynthetic apparatus.

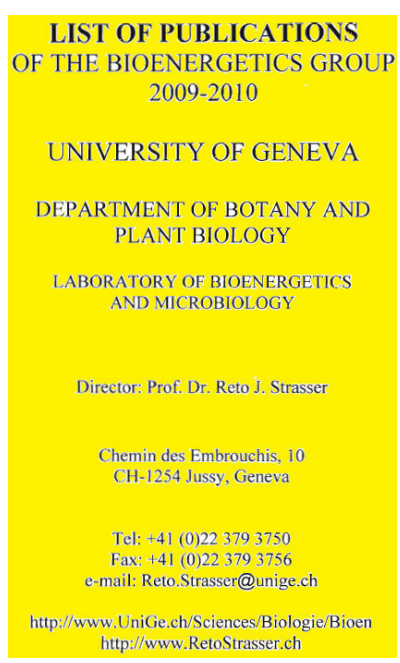

Fig. 4. Last yellow book published in 2010 by Reto Strasser at the Laboratory of Bioenergetics and Microbiology, Geneva University, Switzerland

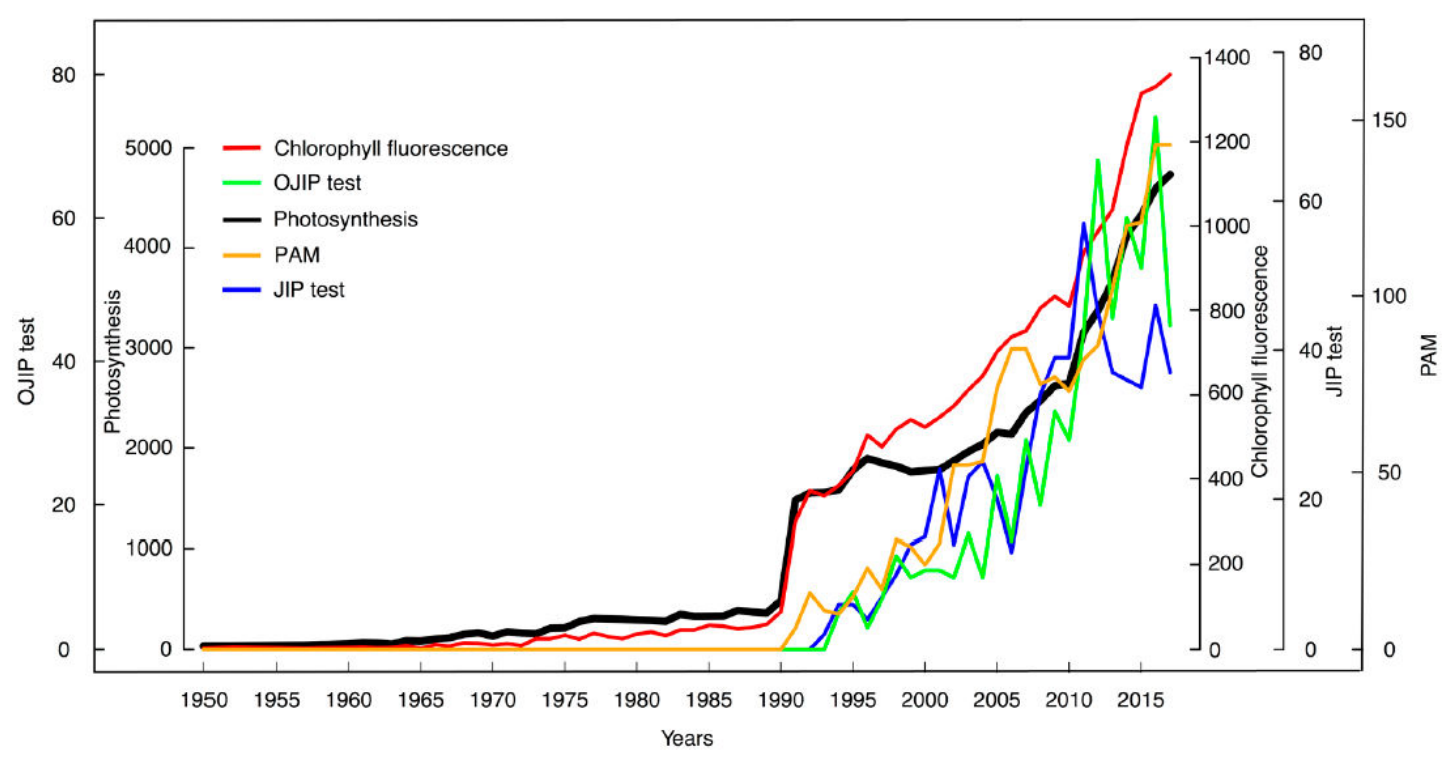

Fig. 5. The annual increase in number of publications found in Web of Science Core Collection related to keywords: 'chlorophyll fluorescence', 'photosynthesis', 'JIP test', 'OJIP test', and 'PAM' (Pulse Amplitude Modulated Fluorescence) (Bąba et al. 2019). 


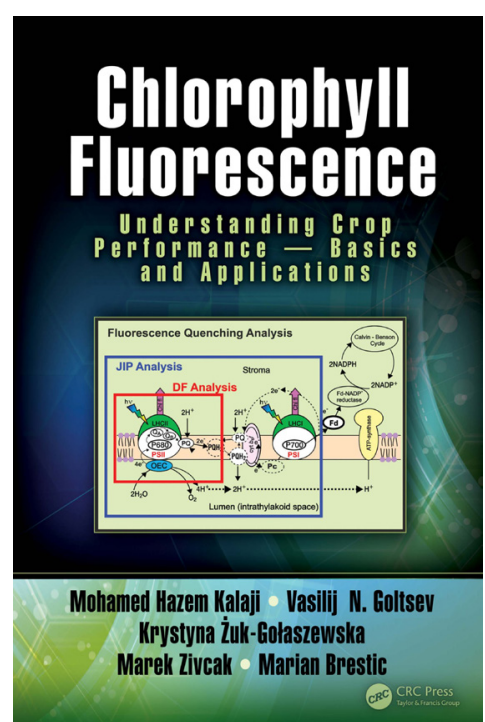

Fig. 6. One of the best books published in the last years (2017) by CRC press by Kalaji et al. that includes ample information about JIP-test and other techniques for measuring and analyzing data related to chlorophyll $a$ fluorescence. Some scientists call it "The Bible of Chlorophyll Fluorescence Measurements".

dependent phase of photosynthesis (Fig. 7).

Reto has been involved in developing instrumentation used for measuring the efficiency of photosynthesizing organisms. He has collaborated for more than 30 years with Hansatech Instruments Limited (UK). They developed the first Plant Efficiency Analyzer in the world (PEA) in 1989 and then subsequently the Handy PEA as the next generation of these instruments (Fig. 8).

In the last 15 years, Reto and Hansatech Instruments

JIP-Test fluxes of R.J. STRASSER, placed into any Z-Scheme

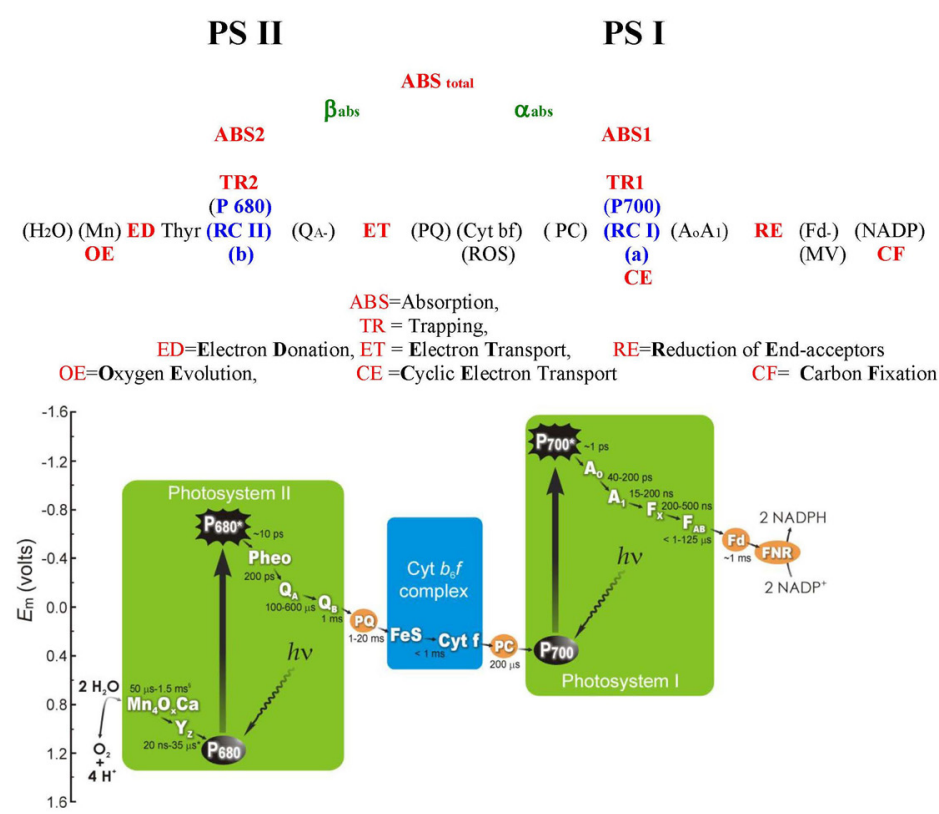

The Z-Scheme (Courtesy of Dmitriy Shevela)
Limited, along with Prof. Vasilij Goltsev, have been working on an instrument that can measure more than the fluorescence signal which can be recorded by Handy $P E A$. This work culminated in the M-PEA (Multi-Function Plant Efficiency Analyser) a sophisticated instrument that combines high-quality fast fluorescence kinetics and $\mathrm{P} 700^{+}$absorbance studies and ground-breaking delayed fluorescence (DF) measurements to provide one of the most comprehensive systems for the investigation of plant photosynthetic efficiency available (Fig. 9).

$M-P E A$ (model MPEA-2) includes both the prompt and $\mathrm{P} 700+$ acquisition elements in conjunction with delayed fluorescence measurements, leaf absorptivity measurements (Fig. 10). During recent years, much valuable research has been conducted (with many publications) by Prof. Vasilij Goltsev, Department of Biophysics and Radiobiology, Sofia University "St. K1. Ohridski", 1164 Sofia, Bulgaria, showing the potential of $M-P E A$ device.

Reto has cooperated/supervised more than 100 scientists, who later became ambassadors for JIP-test research in more than 30 countries including Austria, Brazil, Bulgaria, Canada, China, Czech Republic, Germany, Greece, India, Indonesia, Iran, Italy, Japan, Netherland, Pakistan, Poland, Russia, Slovak Republic, South Africa, Turkey, United States of America, and many other countries. Due to this, Reto took a core position in chlorophyll $a$ fluorescence research (Fig. 11) (Bąba et al. 2019).

At the end of this modest work, we would like to thank Helena Synková (Editor-in-Chief) and Ivana Štětinová (Executive Editor) of Photosynthetica for their outstanding work and passion in creating this Special Issue.
Fig. 7. Artwork by Dimitriy Shevela. The scheme combines the Z-scheme and JIP-test which is based on the energy flux theory (Shevela 2008). 


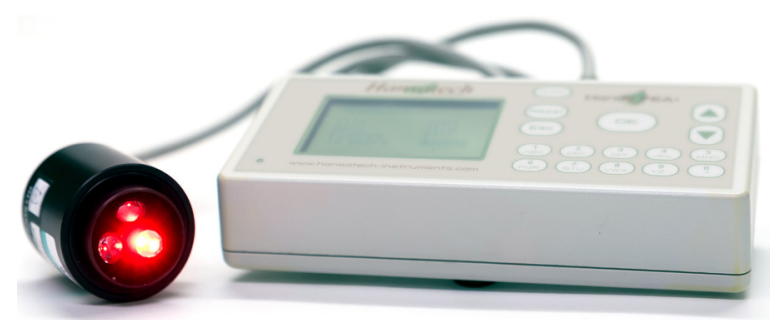

Fig. 8. Handy PEA consists of a compact, lightweight control unit encapsulating sophisticated electronics. This provides the high time-resolution which is essential in performing measurements of fast chlorophyll $a$ fluorescence induction kinetics (Courtesy of Hansatech Instruments Limited, UK).

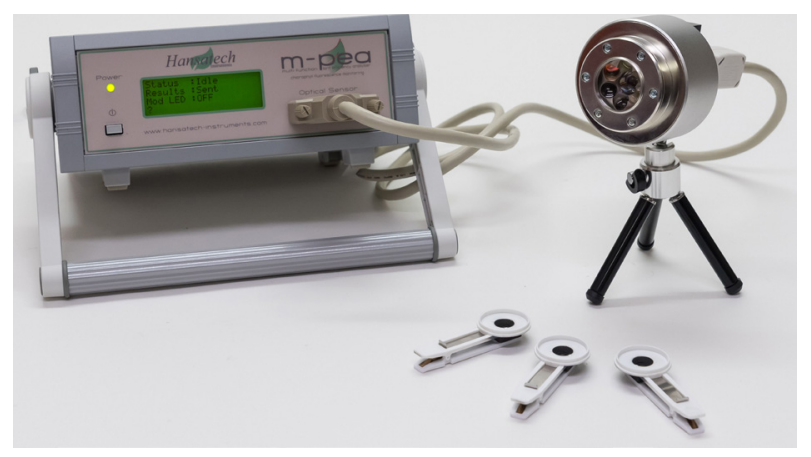

Fig. 9. The M-PEA (Multi-Function Plant Efficiency Analyser) developed by Hansatech Instruments Limited in cooperation with Prof. Reto Strasser and Prof. Vasilij Goltsev (Courtesy of Hansatech Instruments Limited, UK).

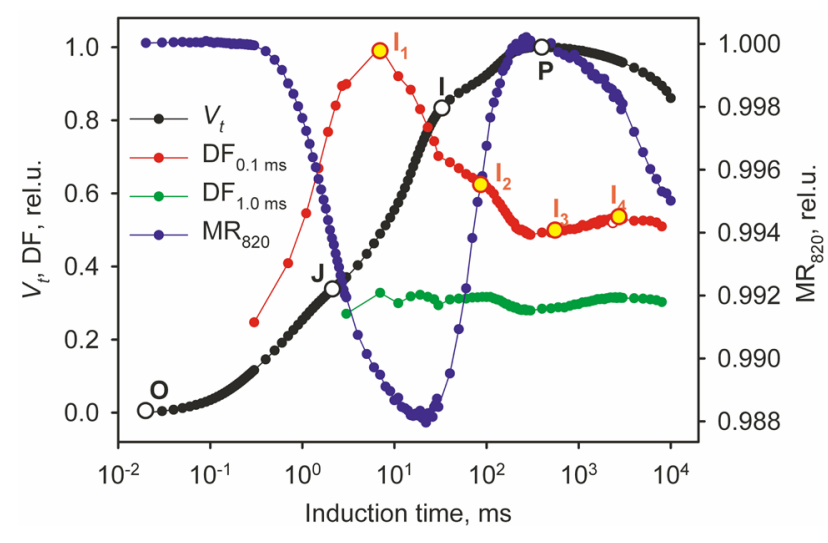

Fig. 10. Induction curves of relative variable fluorescence $\left(V_{t}\right.$, represented on the left axis of the graph); the delayed fluorescence measured at two intervals: from 20 to 90 microseconds ( $\mathrm{DF}_{0.1 \mathrm{~ms}}$ ) and from 0.1 to $0.9 \mathrm{~ms}\left(\mathrm{DF}_{1.0 \mathrm{~ms}}\right.$, triangles, represented on the left axis of the graph); and relative changes in light reflection at $\lambda=820 \mathrm{~nm}$ (MR $\mathrm{MR}_{820}$, presented on the right axis), recorded simultaneously in dark-adapted bean leaves using the $M-P E A 2$ fluorometer. The intensity of the actinic red light was 4,000 $\mu$ mol(quanta) $\mathrm{m}^{-2} \mathrm{~s}^{-1}$. Larger symbols show characteristic points of the induction curves/transients of prompt and delayed fluorescence (Kalaji et al. 2017).

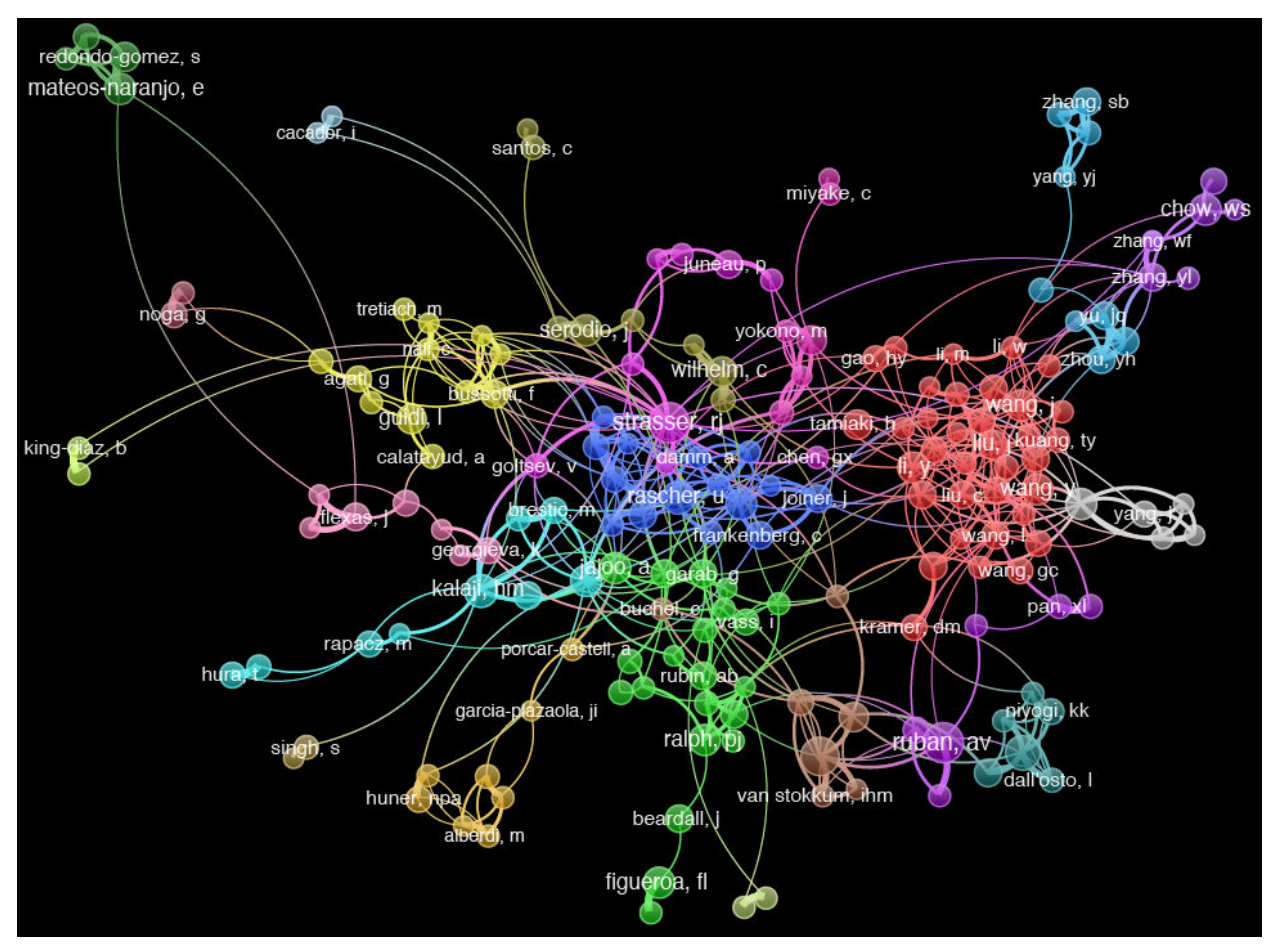

Fig. 11. A scheme showing the central role of Prof. Reto Strasser playing in the wonderful world of photosynthesis. More information can be found in the published recent work by Hu et al. (2020). 


\section{References}

Bąba W., Kompała-Bąba A., Zabochnicka-Świątek M. et al.: Discovering trends in photosynthesis using modern analytical tools: More than 100 reasons to use chlorophyll fluorescence. - Photosynthetica 57: 668-679, 2019.

Govindjee, Srivastava A., Stirbet A., Soni V., Bhalla Sarin N.: Tribute and a Perspective: Reto Jörg Strasser: An innovator, a wonderful friend and "Professor of the World". - J. Plant Sci. Res. 35: 147-158, 2019.

Hu K., Govindjee G., Tan J.et al.: Co-author and co-cited reference network analysis for chlorophyll fluorescence research from 1991 to 2018. - Photosynthetica 58: 110-124, 2020.

Kalaji H.M., Goltsev V.N., Żuk-Gołaszewska K. et al.: Chlorophyll Fluorescence: Understanding Crop Performance Basics and Applications. - CRC Press, ISBN 978-14-9876449-0, 2017.

Kalaji H.M., Schansker G., Brestic M. et al.: Frequently asked questions about chlorophyll fluorescence, the Sequel. Photosynth. Res. 132: 13-66, 2017.

Kalaji M.H., Gert Schansker, Richard J. Ladle et al.: Frequently asked questions about in vivo chlorophyll fluorescence: practical issues. - Photosynth. Res. 122: 121-158, 2014.

Kalaji M.H., Jajoo A., Oukarroum A. et al.: The Use of Chlorophyll Fluorescence Kinetics Analysis to Study the Performance of Photosynthetic Machinery in Plants. - In: Ahmad (Ed.): Emerging Technologies and Management of Crop Stress Tolerance, Vol. 2. Pp. 347-384. Elsevier Inc. 2014

Shevela D.: Photosynthetic Water Oxidation. Role of Inorganic Cofactors and Species Differences. Pp 132. VDM Verlag, Saarbrücken 2008.

Stirbet A., Strasser R., Swizerland: - Ref. List for Yellow Books 01 to $19 ; 1967$ to 2009 Reto Strasser, 2012.

Tsimilli-Michael M.: Revisiting JIP-test: An educative review on concepts, assumptions, approximations, definitions and terminology. - Photosynthetica 58: 275-292, 2020.

\section{Appendix}

Reto Strasser's publications (1967-2020)- see Google Scholar:

Keywords: Reto Strasser chlorophyll (686 publications)

((https://scholar.google.com/scholar?q=Reto+strasser+chlorophyll\&hl=pl\&as_sdt=0\%2C5\&as_ylo=1967\&as_yhi=2020)

Keywords: Reto Strasser chlorophyll fluorescence (698 publications)

Keywords: Reto Strasser JIP (425 publications)

https://scholar.google.com/scholar?hl=pl\&as_sdt=0\%2C5\&as_ylo=1967\&as_yhi=2020\&q=Reto + strasser + jip $\& b t n G=$

Keywords: JIP-test JIP test (2740 publications)

https://scholar.google.com/scholar?hl=pl\&as_sdt=0\%2C5\&as_ylo=1967\&as_yhi=2020\&q=JIP-test + JIP + test\&btnG=

(C) The authors. This is an open access article distributed under the terms of the Creative Commons BY-NC-ND Licence. 